\title{
Communication and Folk Psychology
}

\author{
Richard Breheny
}

\begin{abstract}
Prominent accounts of language use (those of Grice, Lewis, Stalnaker, Sperber \& Wilson among others) have viewed basic communicative acts as essentially involving the attitudes of the participating agents. Developmental data poses a dilemma for these accounts, since it suggests children below age four are competent communicators but would lack the ability to conceptualise communication if philosophers and linguists are right about what communication is. This paper argues that this dilemma is quite serious and that these prominent accounts would be undermined if an adequate more minimal alternative were available. Just such a minimalist account of communication is offered, drawing on ideas from relevance theory and situation theory.
\end{abstract}

\section{Introduction - A Dilemma For Accounts of Communication*}

Prominent accounts of language use and human communication face something of a dilemma. The dilemma arises because it is assumed (a) that basic communicative situations essentially involve propositional attitude-like states of the participating agents and (b) that competent language users have the conceptual abilities to represent agents as being in such

* The ideas in this paper have been presented at different stages of its development over the past three years. At each stage, I have benefited from helpful comments and criticisms. I am particularly grateful to Deirdre Wilson for stimulating and challenging feedback; and to Milena Nuti whose ideas about cognitive faculties inspired me to think in terms of two stages of folk-psychological development. I am also grateful to the pragmatics group at University College London who helpfully attended some long presentations of this material; to audiences at the 2001 ESPP conference in Fribourg, Cogsci 2001 in Edinburgh, the University of Trondheim, the Institut Jean Nicod, Paris, the University of Seville. Particular thanks go to Robyn Carston, Francois Recanati and Dan Sperber. Two anonymous M\&L reviewers also provided helpful comments and suggestions. The paper began life in a discussion with Gillian Brown here in Cambridge and I am grateful to her for forcing me to make clear my ideas about utterances. Work on this paper was partly in collaboration with the European Science Foundation EUROCORES programme "The origin of man, language and languages", project 01-R01: Mindreading and the emergence of human communication.

Address for correspondence: Department of Linguistics, University College London, London WC1E 6BT, UK 
states and make folk-psychological inferences about agents so represented. This assumption conflicts with one of the more robust findings in developmental psychology: that children below the age of four years do not possess these abilities. The conflict arises because it is widely agreed in research on language development that children below the age of three years are competent language users and communicators in the basic sense.

Basic communicative acts can be verbal or non-verbal, but, for the purposes of this paper, let us assume they are typified by the assertive utterance of a declarative sentence for informative purposes (eg 'It's raining.').

There are three obvious strategies for resolving this dilemma:

Strategy I: Argue that two- and three-year old children are not really competent with regards to basic communication.

Strategy II: Argue that children under four years do possess the required abilities.

Strategy III: Argue that these abilities are not required for agents to engage in basic language use and communication, while maintaining that communication is as the elaborate analysis suggests.

One aim of this paper is to argue that none of these strategies is without shortcomings and that these conceptually elaborate accounts would be less appealing given an alternative, more minimalist account of basic communication. A second aim of this paper is to present such a account - one which does not involve propositional attitudes essentially nor presuppose folk-psychological abilities. The minimalist account incorporates ideas from relevance theory, situation theory and current research on the representation of conceptual knowledge of actions. A sketch will also be provided of the development of early conceptual, 
communicative and other social cognitive abilities with which children come to be able to engage in basic communication by about two years of age.

The next section sets out the dilemma in more detail. Section 3 briefly considers strategy I above. Section 4 looks at strategy II. Section 5 sets out a minimalist view of basic communication and its development in early childhood. Section 6 considers possibilities for conceptually more elaborate accounts of communication adopting versions of strategy III. Section 7 concludes.

\section{$2 \quad$ Folk Psychology in Communication?}

The claim in the introduction is that prominent accounts of communication presuppose folkpsychological abilities but that children who are competent communicators lack these abilities. In this section, this claim will be spelt out in detail.

\subsection{Folk Psychology}

Terms such as 'folk psychology' and 'theory of mind' have been used in a variety of more or less technical ways across a range of disciplines - particularly developmental psychology and philosophy. In this paper, 'folk psychology' will be used in a sense most closely related to that in philosophy of mind since it is possession of folk psychology in this sense which is presupposed in the accounts of communication we will be considering. For concreteness, let us adopt the sketch of folk psychology provided in Lewis (1994: 416) who suggests that folk psychology is a largely tacit theory which is nevertheless common knowledge among us. It provides us with a fairly accurate, 'powerful instrument of prediction'. It concerns the causal 
relations of mental states, perceptual stimuli and behaviour.

In philosophical discourse, folk psychology is assumed to underlie the kind of everyday explanations of actions which include propositional attitudinal states among their reasons. It is acknowledged that such accounts cannot be cast solely in terms of desire. When John switches on an electric kettle, we can say he does this because he wants to boil water, only if he knows what the kettle is for, how it works and that there is water in it. So, folk psychology needs to include a doxastic mental-state term akin to 'belief' which is functionally interrelated with an attitude term for desire.

Folk-psychological abilities, on this understanding, include modal inferential abilities. Modal inferential abilities do not just include the ability to entertain thoughts and assumptions about counterfactual states of affairs. They involve the ability to entertain epistemic alternatives generally. Behaviour can be caused by states divergent from our own whose content is not incorrect but merely incomplete. For example, even though free tickets to a show are being distributed near to the box office, if John does not know this and he wants to see the show, he will still purchase tickets.

The claim in the introduction is based on one of the more robust set of findings in experimental developmental psychology. This is that children below age four systematically fail to show evidence of key folk-psychological abilities. The most well-known result involves false-belief tasks. These tasks require subjects to predict the behaviour of another agent who has false information, or to talk about another agent's false beliefs. A description of this task follows:

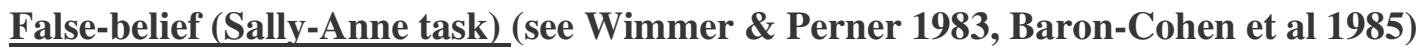

Puppets Sally, Anne and Sally departs. Anne Sally returns. Subject is asked, 
subject play with sweetie. moves sweetie from 'Where does Sally think her Sally places sweetie in container A to container sweetie is' container A. B.

An alternative task involves the same scenario with the question, 'Where will Sally look for her sweetie?'. Children below the age of four years systematically tend to give the wrong answer (container B) in both tasks while there seems to come a point around four years where children start getting it systematically right. The robustness of the result has recently been demonstrated in Wellman et al's (2001) meta-analysis.

Beyond the much studied false belief-task, other research has tested the ability to talk about behaviour of agents who have incomplete information, rather than false beliefs. It seems that even at age four, few children demonstrate an understanding of the relationship between knowledge and intention and even fewer seem to have a grasp of the interaction of knowledge, desire and intention (see Joseph \& Tager-Flusberg 1999). A description of one experiments testing this follows:

\section{Lack of information task (Joseph \& Tager-Fluchberg 1999)}

$\begin{array}{lll}\text { A boy and girl puppet are } & \text { The boy puppet is } & \text { Both boy puppet and girl } \\ \text { introduced into separate } & \text { blindfolded and cannot see } & \text { puppet knock over the pile } \\ \text { rooms with separate piles } & \text { the blocks. The girl can. } & \text { of blocks. } \\ \text { of blocks. }\end{array}$

Two questions are asked: Who knew where the blocks were? and Who was trying to knock the blocks over? Around half of three year olds answered the knowledge question correctly 
while $82 \%$ of four year olds answered the knowledge question correctly. Only $16 \%$ of three year olds answered the intention ('try') question correctly and only $45 \%$ of four year olds got the intention question right.

\subsection{Communication}

It may have occurred to the reader that there is a very well-known account of communication which does not necessarily imply folk-psychological abilities on the part of communicators. This is the code model of communication. According to the code model, an utterance has an interpretation which is fixed by some deterministic set of rules applied to the utterance's form. However, according to a very broad consensus, the code model cannot really be the whole story about communication. While arguably many words can be said to encode a fixed meaning ("cat", for instance) or can be interpreted relative to a deterministic rule ("I"), almost all utterances contain components whose interpretation is non-deterministic on most accounts. A well-known illustration of the problem involves the pair of example discourses in (1). Although we may have firm intuitions about who the pronouns in the second sentences would refer to, it is not difficult to construct a plausible story - consistent with the best theories of the semantics of English - whereby they could refer to the other group:

(1) a. The town councillors refused the protestors permission to demonstrate. They feared a riot.

b. The town councillors refused the protestors permission to demonstrate. They were anarchists.

Although third-person pronouns are the paradigm case of an expression underspecifying 
interpretation for an audience, there are very many other expressions in natural language which have some kind of contextual variation (see Cartson 2001, Stanley 2000). In addition, most sentences of English have a great degree of syntactic and semantic ambiguity given the huge variety of word senses, scope possibilities and so forth. The result is that almost no utterances can be understood by some kind of deterministic, decoding process. Indeed, in the context of natural language processing, the problem of utterance interpretation is referred to as 'AI complete" ${ }^{1}$ - meaning that interpretation requires large amounts of reasoning with common sense knowledge.

So, in providing an account of interpretive aspects of language use we are obliged to say something not only about the conventional meaning of the language used but also about how the various indeterminacies arising from the conventional meaning are resolved. It seems that we need an account of communication whereby the participating agents can achieve some co-ordination of signal and message with more than encoding and decoding.

\subsection{Children and Communication}

We should note at this stage that pronouns ('he', 'that' etc) are among the first words that children master (Bloom 2000). So we can assume they have a basic competence when it comes to inferring what referents these context-dependent expressions have. More generally, by age two, children are quite good at dealing with the manifold indeterminacies in utterances. But interestingly, there are quite distinctive limitations to children's performance when it comes to language use and communication. In situations where successful communication requires the participants to exercise folk-psychological abilities, children

\footnotetext{
${ }^{1}$ The description is attributed to Robert Wilensky in Jordan \& Russell (1999: 1xxxv).
} 
below age four predictably get things wrong. In this regard, consider Mitchell et al's false belief task with descriptions:

\section{The False-Belief Task with referring expressions: (Mitchell et al, 1999)}

Experimenter1 and Subject Experimenter2 comes and Experimenter 1 calls from

play with two cars. E1 puts switches cars. (now red car an unsighted position,

blue car in toy garage and is in garage etc). 'Bring me the car in the

red car on toy road. E1 garage.'

leaves.

The results of this experiment indicate that children below four years fail, assigning as

referent to 'the car in the garage', the car which is actually in the garage and not the one the speaker would think is in the garage.

It is also becoming apparent that children below age four don't really infer even the most mundane conversational implicatures where the inferences would uncontroversially require folk-psychological abilities. A case in point involves the so-called scalar implicature that not all Fs G which normally can be inferred from assertive utterances of 'Some Fs G' (see Noveck 2001, Papafragou \& Mussolino 2003). Quite remarkably, children treat "Some elephants have trunks" as a logician would, not finding anything untoward about such an utterance; whereas the majority of adults tested by Noveck (2001) actually judged such an utterance false. According to any account of these scalar implicatures (see Gazdar 1979), making the inference would involve folk psychological abilities at a number of points. Most uncontroversially, making the inference involves thinking counter-factually about what the speaker could have alternatively said were a more informative or relevant proposition true. It also involves thinking about what kind of grounds could have furnished the speaker's 
utterance.

These results square with everyday experience: young children are quite poor at interacting with others where the others' beliefs, desires or intentions are relevant to the interaction. For instance, a distinctive quirk of young children is to sometimes give unexpected or unhelpful answers to questions. A child asked by someone, "Where is your mother?" might unhelpfully answer, "Out" where it would be clear to an adult interlocutor that more specific information is required or an 'I don't know' otherwise. Adults can normally take it for granted that interlocutors could infer what kind of answer would serve the questioner's current needs, even where these needs are unspoken. While children correctly understand questions as directives to provide an answer, without folk-psychological abilities, they often have no idea why they are being asked to provide an answer, offering information that is currently most relevant to them. In the situation described, any adult would, by default, understand the questioner as wanting to find the mother, and thus that some specification of her location suitable to the purpose finding the mother would be required. Without folk-psychological abilities, a young child would not have made the link between a question and the questioner's desire for something (information).

\subsection{Action-Oriented Accounts of Communication}

Given the great amount of indeterminacy of a linguistic signal with regard to its message and the great underspecification of interpretation by most sentences' meanings, a lot of the explanatory burden of how utterances are understood is passed over to accounts of extralinguistic principles of language use. These pragmatic accounts in turn are built around analyses of our concepts of symbolic transactions. Most such analyses take as primary the 
actions of the speaker or the interactions of speaker and hearers. ${ }^{2}$ In this sub-section, well known action-oriented accounts will be considered and shown to presuppose full folkpsychological abilities on the part of language users. Ultimately, the presumption of full folkpsychological abilities as an essential component of communicative interactions can be traced to some assumptions about specific features of speech acts which, if they were actually essential features, would indeed mandate folk-psychological abilities on the part of conversational participants. ${ }^{3}$ The source of virtually all currently prominent action-oriented accounts of comprehension is Grice whose ideas we examine first.

2.4.1 Grice on Meaning Although Grice had a view on the nature of basic speech acts

${ }^{2}$ Although text-oriented accounts of discourse exist, these tend to leave out of their account non-verbal communicative acts and one-word or two-word or even one-sentence utterances, focussing only on quasi-conventional stylistic constraints in various types of monologue. Although it is conceivable that a case could be made that rhetorical constraints on discourse do not derive ultimately from facts about utterances-as-actions, it seems most plausible that they do. (See Asher 1999 for a text-oriented view of this issue). As our interest here is in accounts of basic human communication - whether verbal or non-verbal - and how children from about 12 months old engage in such behaviour, we will pass over text-oriented accounts.

${ }^{3}$ The common practice of using 'utterance' and 'speech act' to refer to acts other than those involving speech - those where communication or other typical functions of speech acts are intended - is adopted here. Mutatis mutandis, 'speaker', 'hearer' and 'audience' for the participants in speech-act situations. 
which will be considered below, his main concern was with speaker meaning - a feature of all speech-act scenarios. For Grice, there is an intuitively distinct sense of 'means', means $s_{N N}$ which applies to utterances and is related to a reflexive, M-intention. The core definition is given below:

'U meant something by uttering $\mathrm{x}$ ' is true iff, for some audience A, U uttered $\mathrm{x}$ intending:

(i) A to produce a particular response $\mathrm{r}$

(ii) A to think (recognise) that U intends (i).

(iii) A to fulfill (i) on the basis of his fulfilment of (ii).'

(Grice 1969/1989:92)

Recovering what is meant by the speaker's utterance then is a matter of recovering the content of what he or she meant $\mathrm{NN}_{\text {. }}$

It is worth reflecting on this definition to make clear that Grice really did presuppose full folk-psychological abilities on the part of speaker and audience. In both 'Meaning' (Grice 1957/1989) and 'Utterer's meaning and intention' (Grice 1969/1989), Grice comments on the third point of the definition stressing that the recognition of U's intention should serve as a part of A's reason for producing $r$ - as opposed to the fulfilment of (ii) being just any kind of cause of A's fulfilment of (i). So in order to think about meaning ${ }_{N N}$, one needs to be able to conceive of an action directed toward a doxastic mental state of another (A) - to engender the thought that $\mathrm{U}$ intends $\mathrm{A}$ to produce $r$. It is a belief state moreover which plays a role typical of such states in folk psychology - i.e as a reason for action. In this case, the uttering of $\mathrm{x}$ is an action, part of whose goal is that the thought that $\mathrm{U}$ has an intention that A produce $\mathrm{r}$ be a reason for A producing $r$. Effectively, Grice presupposes in the third clause a core assumption 
of folk psychology which links intention to belief - as described above.

Grice also conceived of typical speech acts as having an effect on the audience's attitudes as their primary goal. For instance, the Gricean view of basic assertive utterances is that they are cases where the response, $r$, in (i) above is the formation of some belief or other. ${ }^{4}$ So, in a basic communicative scenario, as where the speaker says assertively, "It's raining", we would conceive of the speaker's goal as being, in part, to engender the thought in us that he intends us to form the belief that it is raining, and, in part, for this thought about the speaker's intentions to be among the reasons why we form the belief that it is raining. But intuition suggests that if the speaker is between two and three years of age, we would be happy to say that she meant something (in the intended sense). So, assuming the developmental evidence is not misleading, we have the dilemma mentioned in the introduction. Correspondingly, the Gricean could argue one of the following: that we would be mis-attributing meaning to the child's utterance; that the developmental evidence is

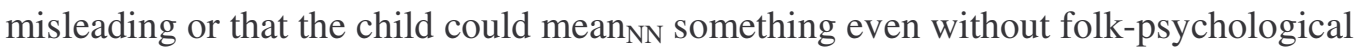
abilities. The options will be considered below. First, other conceptually sophisticated accounts of our basic communicative scenario need to be mentioned.

2.4.2 Beyond Grice In the midst of Grice's analysis, lies the familiar structure of a certain type of interactive scenario. When a speaker wants to communicate something or perform some other type of speech act, he or she needs, in some way, the attention and compliance of the audience. These features are captured, respectively, in conditions (ii) and (i) of Grice's

\footnotetext{
${ }^{4}$ See Grice (1969/1989: 123) where he suggests that assertive utterances have as
} primary goals to induce beliefs about the speaker's beliefs. 
definition of Meaning $\mathrm{N}_{\mathrm{NN}}$. The third condition adds a folk-psychological dimension which doesn't necessarily figure in similar scenarios. Consider, by way of contrast, a game of pat-aball. When A bats the ball in the direction of $\mathrm{B}$, all that is required for the game to continue are conditions similar to (i) and (ii) above: that B is aware of what is going on and would join in. Although perhaps in very competitive, sophisticated games, A and B may employ folkpsychological abilities for the purpose of gaining advantage, the game in its essence can be played by beings who lack a folk-psychological awareness - such as trained seals. Grice's third condition, as Schiffer (1972:58) observes, is included on the assumption that symbolic transactions are instituted as an activity among rational, reflective agents aimed broadly at the production of beliefs or other attitudes.

All other prominent accounts of speech acts to be considered here make the same kind of basic assumption. In fact, the currently prominent view of speech acts would add a further feature to utterance scenarios which independently necessitates the exercise of folk psychological abilities. The presence of this further component relates to a well-known type of counter-example concerning the sufficiency of Grice's original definition of meaning $\mathrm{NN}_{\mathrm{N}}$. The counterexamples involve so-called 'sneaky' intentions. These are cases where the three conditions above are fulfilled but where U's intention that A recognise U's intention that A respond appropriately is hidden. The diagnosis of this problem which has become broadly accepted is that meaning and/or communication requires some form of explicitness or overtness about the actions of the speaker. What is then normally added to the analysis of utterance scenarios is a mutual knowledge/belief/assumption condition. The condition requires that all factors relevant to establishing the speaker's M-intention be mutually known/believed/assumed. This was added by Schiffer (1972) in his analysis of meaning NN $_{\text {. }}$ Mutual knowledge, belief, and assumption are effectively propositional attitudes, having 
similar modal properties to belief and capable of playing a similar role in folk-psychological explanations (see Stalnaker 1998).

Schiffer's analysis of meaning in terms of mutual knowledge makes utterance situations games of co-ordination. It was preceded by Lewis' (1969) game-theoretic analysis of conventional meaning. Subsequent work in pragmatics in either the game-theoretic framework (see Parikh 2001) or outside (cf Stalnaker 1979) exploit Schiffer's added condition. The leading idea is that the features of context which are needed to establish what proposition an utterance expresses are part of what is mutually assumed, or common ground. Establishing what a speaker means therefore boils down to co-ordinating on what is commonly assumed. In practice, arriving at a solution to a co-ordination problem involves having at least what Lewis calls second-order expectations. These are expectations about other players' expectations.

In summary: reflecting on basic communicative situations, analysts have been impressed by the necessary overtness of the acts in question and/or by the apparent fact that such acts have an effect on the attitudes of the participating agents as a prototypical goal. Now, if communicative acts really were directed at the attitudes of the audience, or if overtness really did mean mutual knowledge/assumption of the relevant contextual facts, then there is no denying that communicating would be constituted such that folk-psychological states would be essential features. Also there would be no denying that individuals capable either of grasping what communication is or engaging in communication require folkpsychological abilities. On the other hand, if the developmental data is not misleading, then the above suppositions seem to overstate things. In the next two sections, the first two strategies mentioned in the introduction will be critically considered. A critical consideration of the third strategy requires there being a viable minimalist alternative available. That 
alternative will be presented in Section 5 before the third strategy is considered in Section 6 .

\section{Strategy I: Denying that Children Below Four Years are Competent Communicators}

The viability of Strategy I depends on how easily one can overturn the prima facie intuition that young children, aged two to three years, are capable communicators in the following sense: in at least some cases, their use of language or their understanding of others' use of language is at a level of performance equivalent to that of an adult. That is, in at least some

situations when a child utters a sentence, $\mathrm{S}$, their intentions are clearly comprehensible and are the same as those a normal adult would be attributed with if she uttered $\mathrm{S}$ in the same circumstances. Similarly, in at least some cases where children are faced with an utterance of S by another agent, their grasp of that action is the same as that of an adult faced with the same utterance. In particular, when it comes to basic, assertive communicative acts, it seems clear that children often display adult competence.

Of course, as already suggested above, children of this age are not nearly as good at communication as adults. They are much more prone than adults to misunderstanding, miscommunications, irrelevancies and ungrammaticalities. Also their linguistic proficiency is in many ways not the same as adults'. In particular they have a much more limited vocabulary. But this is a matter of degree. They do have the basic wherewithal to engage in linguistic communication, in spite of the fact that their cognitive capacities limit the degree of success in this matter.

For us to take strategy I seriously, we would need a lot more evidence that children 
are not competent when it comes to basic communication. Presently, it does not seem all that likely that this evidence would be forthcoming. Consider, in particular, the fact mentioned above that third-person pronouns ('she', 'he', 'it' etc) are among the first words children learn and that their usage of these forms evinces a more or less adult competence in circumstances where there are no extra demands placed on the child which are beyond their conceptual abilities. This particular fact is significant, given that many semantic and pragmatic theories of pronoun usage attach sophisticated presuppositions (involving the common ground) to pronouns (see Stalnaker 1998) while certain pragmatic theories would include pronoun reference resolution as part of a pragmatic process which would involve folk-psychological concepts. In the absence of any strong arguments for this option, it will be put aside.

\section{Strategy II: Denying that Children Below Age Four Lack Folk- Psychological Abilities}

As mentioned above, the evidence available suggests that even at age four, children have but a tenuous grasp of the connection between belief and intention. So, on the face of it, they would be unlikely to conceive of an utterance's goal as being the engendering of a belief which in turn is meant to be a reason for acting. In order to make strategy II work, we would need to be convinced that, really, children between two and three years of age have the appropriate cognitive abilities presupposed by the prominent accounts of communication. In this section it will be argued that there is no good reason to think that children of three years have a conception of belief adequate to grasp a complex reflexive intention of the sort Grice 
used to analyse meaning. It would follow that they would not posses the capacity to contemplate mutual knowledge, belief or assumption. A fortiori, children between two and three years would not have the requisite abilities.

\subsection{Two Views of the Development of Folk-Psychological abilities}

Beyond the philosophy of mind, much has been written about the human tendency to 'mindread'. Indeed, it is rapidly becoming clear that a distinguishing feature of humans relative even to the most closely related primates is a precocious ability to think about psychological states (Tomasello 1999). It also seems quite clear that there is a universal human developmental trajectory beginning at age 9-12 months and ending some time around four years. It begins with children showing signs of an awareness of self and others as 'intentional agents' - in some sense of that term. It ends with children able to engage in practices which indicate possession of something approaching a fully-fledged folk psychology.

There are a number of different kinds of accounts of the cognitive development of a child's psychological understanding but not all are consistent with the claim that children have the requisite folk-psychological competence to grasp meaning $g_{\mathrm{NN}}$ at around the time they become competent communicators. Dividing all developmental accounts into those that are favourable to Strategy II and those that are not, one finds that the former accounts mostly assume that the human developmental trajectory is primarily toward some form of folk psychology (Leslie 2000, Gopnik \& Wellman 1995). Other accounts tend to view the development of folk psychology as a secondary process, resulting from a child's reflection on an independent and antecedent development - that of a rich and uniquely human understanding of action. (see Tomasello \& Rakoczy 2003, Nuti 2003). The latter kind of 
model will be adopted in the minimalist account of communication given below. Let us call the former models Strategy-II (S-II) accounts. There are two broad categories of S-II account and although their differences are immaterial to the arguments that will be put forward below, it is worth noting what these differences are.

Of those accounts which presuppose that the arc of a child's development in the domain of psychology is toward a fully-fledged folk psychology, there are those who would propose that children do in fact have a concept of belief from a very early age - around two years perhaps. We can refer to this as the 'theory-of-mind-mechanism account' ('ToMM account' for short), whose chief proponent is Alan Leslie (see Leslie 2000). According to this account, children have a dedicated cognitive mechanism whose primary domain includes the attitude relations wanting, believing as well as the activity perceiving (German \& Leslie 2001). This mechanism begins to mature in the second year and has the job of 'attending to other people's mental states' (G\&L 2001:61) allowing the relevant relation to be 'specifically and reliably dealt with' (ibid). The idea is that children could have concepts of belief and desire without having yet built up much knowledge about these relations through attending to mental states.

Implicit in Leslie's position is a distinction between concepts and any associated knowledge structure (conception) which builds up around these. In principle, one can have a concept of something without having much of a conception of what that thing is. This principle follows from extensionalist ideas about mental content (see Putnam 1975) and concept individuation (Fodor 1998).

The alternative S-II account to the ToMM approach is the 'theory-theory' position of Wellman, Perner and others. On theory-theory accounts, young children do not have a concept of belief as such but a (false) folk-psychological theory which implies the existence 
of a belief-like state. Thus young children have a belief-like concept which differs from an adult belief concept in certain of its implications. The question as to what are the differences between the belief-like state of the early theory and belief can be answered at least in part by pointing to performance on false-belief tasks. Whatever incorrect assumptions are responsible for this behaviour are among those that need to be revised in order for a child to have developed a fully-fledged folk-psychology and proper conception of belief.

According to both S-II accounts, young children's conception of the mental life of others has some kind of deficiency when it comes to false belief. What is possible on both kinds of account is that children have an adequate, functional conception of true belief. It is therefore possible, on either account, that children could form a conception of meaning $\mathrm{NN}_{\mathrm{N}}$ or mutual belief which would be functional to some extent. ${ }^{5}$

\subsection{Conceptions of Belief and the False-Belief Task}

The notion of belief as it figures in folk psychology is modal in nature. Thus modal inferential abilities are required of an individual to form some conception of it. Beyond studies of psychological abilities, results such as in Zaichik (1990), suggest that children lack the ability to think about counterfactual states of affairs. Clearly, such an ability is essential for both fully developed modal inferential abilities and an adequate conception of belief. But, as discussed above, the modal nature of the belief relation is evident even where false beliefs

${ }^{5}$ In fact, from Leslie's perspective, one could suppose that children have some kind of innate concept of speaker meaning, just as they have an innate concept of belief. In section 6 , the proposal that a child could have a Leslie-style mechanism for meaning $\mathrm{NN}_{\mathrm{N}}$ will be considered as a manifestation of strategy III. 
are not involved. Our ideas about other agents' mental states are such that they may simply lack information about some fact and we can explain their behaviour on the basis of this absence as well as on the basis of false information. ${ }^{6}$ The logic of belief reflects the two ideas of having information and having misinformation: there is no implication from $p$ to a believes $p$ and there is no implication from $a$ believes $p$ to $p$. A fully developed conception of belief will reflect these facts. Indeed, it would be reasonable to suggest that an individual who did not show evidence of being aware of either of these facts could not be attributed with a concept of belief or a functional belief-like concept. However, in this section we are not interested in whether a child has a concept of belief, only that it has a conception of belief adequate for grasping meaning $\mathrm{NN}_{\mathrm{N}}$ and mutual belief.

There are two conceivable kinds of account of children's deficiency when it comes to false beliefs. One is a competence account. The other is a performance account. On the competence account, the proposal would be that lacking a conception of false belief, young have not grasped that there is no implication from a believes $p$ to $p$, but that they have grasped the idea that $p$ doesn't necessarily imply a believes $p$. On the performance account, children's competence regarding belief may imply that beliefs can be false but other factors cause them to respond improperly in the false-belief task itself. In this vein Bloom and German's (2000) performance-based explanation for why children fail involves two ideas: (i) that children assume that beliefs are normally true. So even if a child knows beliefs can be false, overriding the basic assumption imposes great processing demands; (ii) that the way the world actually is exerts a 'realist pull' on children when there are multiple representations -

\footnotetext{
${ }^{6}$ There is a weak sense of 'information' which includes false information. This is the sense intended here and elsewhere in this section.
} 
leading them to have difficulty representing states of affairs which conflict in some way with what is actually the case. Neither of these accounts seems to be satisfactory.

Given the currently available data, it does not seem as though the competence account is a viable position. The data in question concern the results of Joseph \& Tager-Flusberg (1999) and the false-belief task itself.

As discussed above, Joseph \& Tager-Flusberg test children's abilities to respond appropriately where the agent in question has only insufficient information. To pass this task, one needs to be aware that $p$ does not necessarily imply a believes $p$, but one does not have to know that the inference the other way is also blocked. The result is that even for four year-old children this is difficult. This result squares with the various suggestions in the literature about early belief-like concepts. These have variously been described in terms of a 'copy theory', a 'Gibsonian theory' or a 'situation theory' of belief (see Gopnik \& Wellman 1995 for discussion) and they imply a non-modal nature of children's understanding of epistemic states. This latter idea is normally discussed in terms of children lacking a 'representational theory of mind'?

Lacking a representational theory of mind just means lacking any of the appropriate modal inferential abilities but this fact has sometimes been overlooked by researchers whose attention is normally drawn to the difficulty children have with false belief. However, even the false-belief task provides evidence that children lack the ability to deal with true beliefs. If the competence account were correct, then in the Sally-Anne tasks we would predict not

\footnotetext{
${ }^{7}$ It will be suggested below that the appearance of a 'non-representational concept of
} belief' has more to do with children's emergent ability to keep track of which agent has experienced which source of information. 
that children below age four systematically fail but that they score more at chance levels.

Let us suppose that in each Sally-Anne task the ball ends up in box B. So the subject will think that the ball is in box B. Let us refer to the proposition that the ball is in box B as $p$ and that the ball is in box A as $q$. (Note $\mathrm{p} \leftrightarrow \neg \mathrm{q}$ ). Given the competence account, we can assume that the subject has an idea about basic ways beliefs are acquired. Eg, the subject will be disposed to infer that Sally believes that John sleeps if Sally sees John sleep. Also, if a child has an adequate conception of true belief, then he or she will at least know that one cannot necessarily make the inference $p \rightarrow$ a believes $p$. By contrast, if subjects have difficulties with reasoning about beliefs about non-actual states of affairs they may be inclined mistakenly to infer $p$ just from $a$ believes $p$.

On these assumptions, however, when young subjects are asked, 'Where does Sally think the ball is?' we would expect there to be some confusion: On the one hand, the subjects have no evidence that Sally believes p. So they have no reason to say that Sally thinks p. On the other hand, they had evidence that Sally believes q. According to their supposed mistaken assumptions about belief, Sally believes $q$ would imply $q$ and $q$ is incompatible with the current frame of reference in which $p$ is true. The result should be more equivocal numbers for the tests. But, the result is that children below age four systematically and confidently choose the wrong answer. The natural diagnosis for children systematically getting the wrong answer seems to be that they misunderstand 'believe', 'think' such that $p \rightarrow$ a believes $p$.

It is important to stress that this 'think'-version of the false-belief task tells us as much about children's ability to deal with true belief as false. This is why Bloom \& German's performance-based account is not so convincing either. The first kind of performance-related factor proposed by Bloom \& German concerned the assumption that an agent's beliefs are true and the fact that children would find it difficult to override heuristics 
based on this assumption. Even assuming such heuristics are used, it would not account for the data since by assumption these children at least know that beliefs have to be formed. In other words, the problem is not with assuming that what is believed is the case, it is assuming that what is the case is believed. And here the second factor may have more relevance. This was that children have difficulty overcoming the 'pull of reality' when it comes to stating what the contents of a conflicting representation are. But then again we have a suggested performance limitation which would need to be overcome in order that children could develop modal inferential abilities in the first place - the very abilities which are necessary for children to form a conception of true belief. So, we can agree that this 'pull of reality' would explain why children give the wrong answer. But one must also concede that this performance limitation would also mean that children could not form the appropriate conception of belief.

To sum up: For a child to have folk-psychological abilities minimally presupposed by the conceptually elaborate accounts of communication, he or she would need some conception of belief which could function in folk-psychological explanations. Such a conception is still modal. It still requires a 'representational theory of mind'. In this section, it has been argued that the available evidence suggests that children at three years lack any such conception. It seems then that strategy II is not an available option for proponents of a conceptually more elaborate notion of communication.

\section{An Action-Oriented Account of Basic Communication Which Does Not Presuppose Folk Psychological States}


In this section, the following questions will be addressed:

\author{
A. What is basic communication? \\ B. How do children below two years of age develop the ability to engage in basic \\ communication?
}

The proposal is that these questions can be answered using the basic ideas contained in Sperber \& Wilson's Relevance Theory and by developing these within the framework of Barwise \& Perry's Situation Theory. Another key component of the proposal draws on nonSII accounts of the development of psychological abilities found in Tomasello \& Rakoczy (2003) and Gergely \& Csibra (2003) - focussing in particular on concepts of actions and their development.

\title{
5.1 Some Relevance Theory and Situation Theory.
}

Relevance theory (Sperber \& Wilson 1986/95) is based on the idea that human information processing is relevance driven. In this theory, the notion of relevance is defined in terms of a kind of cognitive nutrition and in terms of the effort expended in extracting such benefit; viz, the greater positive cognitive effect extracted from a source of information, the greater its relevance; the greater the amount of effort spent in extracting the positive effects, the lesser the relevance. Below, an analogy will be drawn between getting information and eating. In the eating case, positive nutritional effects elicit positive experiences. We assume that positive cognitive effects or relevant information also elicit positive experiences.

Another key element of Sperber \& Wilson's proposals is that we are disposed to 
attend to potential sources of relevance. We can suppose that the amount of attention allocated to a potential source of relevance is determined by a relevance mechanism which fixes a level of nutritional effects (possibly of a certain kind) to be extracted relative to circumstantially determined expectations. When directed to a potential source of relevance, the mechanism operates by following a path of least effort in processing stimuli and stopping when the expected level of relevance is achieved. This is a way of maximising the relevance of the source. So if a potential source of relevance becomes an object of an agent's attention, then that source will be processed for cognitive effects (nutrition) and the process will be halted when the level is achieved (or if there is a failure of some kind, as when the source of information does not live up to its relevance potential).

To give some illustration, imagine driving into an unknown town for the first time in order to stop for lunch. One will have a number of immediate goals - finding somewhere to park and a decent eating place - while driving and obeying the rules of the road. In this case, one is primed to seek out the presence of restaurant-looking establishments, signs which feature the letter ' $\mathrm{P}$ ' prominently etc. But at the same time, one is also disposed to notice interesting, prominent features of the town which happen to catch one's attention. Generally, one's relevance mechanism will divide resources among more immediate goals and a general ongoing goal of improving, or enriching one's representation of the world.

Sperber \& Wilson tend to conceive of the sources of relevance as proximal stimuli for cognitive systems. For the minimalist account of basic communication being presented here, it will be supposed that both the sources of relevance and the objects to which we attend are situations in the sense of Barwise \& Perry (1983), Barwise (1989a). Situations are 'chunks' or 'corners' of reality. Information can flow between situations via more abstract 'channels'. Channels can link non-mental situations to mental situations as well as to other non-mental 
situations.

Although the formal proposals of the theory have been developed somewhat over the years, one core idea of Barwise \& Perry (1983) involves the characterisation of situations using set theoretic objects, in particular, ordered tuples containing properties or relations, individuals, spatio-temporal locations and some indication of polarity. So we can characterise a situation, $s_{1}$, where John is asleep at $1_{1}$ using the ordered tuple, $\sigma_{1}=<$ sleeps, john, $1_{1}$, yes $>$. Tuples such as $\sigma_{l}$ are referred to as 'soas'. We write (2) when the state of affairs so characterised holds in $\mathrm{s}_{1}$ (when $\mathrm{s}_{1}$ supports $\left.\sigma_{1}\right)$ :

$$
\mathrm{s}_{1} \vDash<\text { sleeps, john, } 1_{1} \text {, yes }>
$$

Soas can be conjoined and disjoined and these objects and the concomitant operations constitute something like a Boolean algebra. Situations also have a certain mereology, so that one situation can be contained in another. In particular, for any situations, s and s', there is a (possibly non-distinct) situation s" such that s" contains s and s'.

We can also think of situations more generally as belonging to situation types. Situation types can be characterised using abstract objects called parameters. Given the fact described in (2) above, we can write (3)a,b below. Here bold letters represent parameters, $f$ is a function from the parameters in $\sigma$ to objects of the appropriate type and $\sigma[\mathrm{f}]$ represents the result of replacing parameters in $\sigma$ with their value:
a. $\quad \exists$ f,s $s \vDash<$ sleeps, $\mathbf{a}, 1_{1}$, yes $>[\mathrm{f}]$
b. $\quad \exists$ f,s s $\vDash<$ sleeps, John, l, yes $>[\mathrm{f}]$ 
Although soas function as descriptors of situations, one normally assumes that situations are as finely individuated as the properties and relations which describe them. So we will assume that situations are uniquely identified by a single soa. Given a non-parametric soa, we can say which situation it uniquely identifies. This will be the minimal situation which supports that soa:

$$
\min (\mathrm{s}, \sigma) \text { iff } \mathrm{s} \vDash \sigma \wedge \forall \mathrm{s}^{\prime}\left[\mathrm{s}^{\prime} \vDash \sigma \rightarrow \mathrm{s} \leq \mathrm{s}^{\prime}\right]
$$

Given a situation, $s$, and $\min (\mathrm{s}, \sigma)$ we can speak of $\sigma$ as the type of that situation, $s$.

Channels are situations which carry information between other situations. These have special situation types called constraints. Where a channel links situations s and s' of type $\sigma$ and $\sigma^{\prime}$ respectively, then this channel is a situation where constraint $\Leftrightarrow, \sigma, \sigma \Gamma>$ holds. One can read $<\Rightarrow, \sigma, \sigma 乃$ as: whenever there is a situation where $\sigma$ obtains, there is a situation where $\sigma^{\prime}$ obtains.

We get information about the world by perceiving situations, objects, relations and locations, and by being attuned to constraints. When attending to a situation one can obtain information from it in two ways. A situation will carry information about the type of situation it is via channels linking situations and objects, relations etc. to perceptions of these. Also, relative to channels which link situations of the perceived type to those of other types, a situation will carry information about situations of numerous other types. For instance, when attending to a situation where a state of affairs in which John is asleep holds, one can get the information that John is asleep and, relative to certain constraints, the information that John 
has his eyes closed, that he is not eating soup and so on.

Like all action-oriented accounts of communication, Sperber \& Wilson's account presumes that the comprehension of a given utterance derives from the audience's grasp of the communicator's actions. Some recent advances in the study of concepts of action and their development provide a clue to how communication may have a far more minimal foundation than even Sperber \& Wilson assume - existing independently of the mental states posited by human folk psychology or any similarly complex modal relations.

\subsection{Developing Basic Concepts of Actions}

As mentioned above, there are alternatives to the S-II models of the development of folk psychology. According to these alternatives, the development beginning at 9-12 months of a child's nascent psychological understanding is a separate ontogenetic step from the development of some kind of folk psychology (see Tomasello \& Rakoczy 2003, Nuti 2003). The latter development only comes as a result of reflection on the earlier more basic understanding and presumably only with the onset of the capacity for modal reasoning but aided by the acquisition of certain syntactic constructions. The main features of the earlier development are the development of concepts of goal-directed actions, including the concept of attending to. One aim of this section is to provide some account of early shared-attentional and communicative abilities in terms of some minimal assumptions based on the early child data and the above-described theories.

Additional assumptions about basic concepts ${ }^{8}$ will be made based on the proposals in

\footnotetext{
${ }^{8}$ Here 'basic concepts' denote lexical concepts. In the case of basic concepts of action, it is assumed here that lexical concepts include concepts of actions such as running,
} 
Fodor (1998) as well as Sperber \& Wilson (1986/95) - assumptions similar to those made by Leslie. Formally, basic concepts are assumed to be atomic and their content determined by a nomic mind-world relation. The relation arises due to facts about minds like ours and how they 'resonate' to particular objects and properties in the world. Concept possession is a matter of being in this kind of nomic mind-world relation. Psychologically, basic concepts have associated conceptions - mechanisms which co-ordinate information about important regularities or situation types encountered in relation to their referent. This can include information about sensory experience. The conception-mechanism triggers the activation of representations of this associated information in order to provide context for the processing of current thoughts about, or experiences of, the referent.

Tomasello $(1995,2000)$ among many others provides much evidence that children develop a particularly human conception of goal-directed actions before the end of their first year. This conception identifies what we might call third-person experience of an action with the normal first-person experience which any being capable of planning an action would have. That is, these children could recognise or represent someone else's kicking a ball as the action they would perform when kicking a ball. It is this identification or association which enables humans to have a very intimate grasp of the behaviour of others and, as we will see, to form a concept of shared situations - the basis for what we might refer to pre-theoretically as 'shared experience'. It would also be responsible for any apparent folk-psychological understanding before the establishment of the relevant reflective capabilities necessary for

eating and, of course, communicating. As we will not need to consider complex concepts in this paper, 'concept' will refer to basic concepts and where necessary it will be specified if complex concepts are under discussion. 
actual folk-psychological understanding.

Two types of non-S-II accounts of development are emerging. According to that of Tomasello and his colleagues (Tomasello 1999, Tomasello \& Rakoczy 2003), a very rich understanding of intentional action is developed, and this development partly involves 'sharedness' which in turn involves a 'self-other equivalence' (see Tomasello \& Rakoczy 2003:124). Gergely \& Csibra (2003) suggest that this is a form of simulationism. If that is so, according to some arguments, this non-S-II view is sneaking in much folk-psychological competence under the cloak of 'sharedness' (see the discussion in Gordon 1995 and the references cited therein). By contrast Gergely \& Csibra themselves posit a very impoverished conception of goal-directed action which only encodes statistical regularities about the usual goal states for patterns of perceived activities - i.e. third-person representations only. This seems insufficient to account for the apparent affinity with the experiences of others demonstrated by young children in word-learning experiments (see Tomasello 2000). It will be suggested below that this experiential affinity is crucial to getting young children to grasp the concepts of attending to and, as a consequence, communication. As for Gergely \& Csibra's central idea that children bring an innate rational principle to bear on inferring goals from situated action, this clearly can be adopted by any current non-S-II account and it seems quite appealing.

It is not necessary, however, that a richer conception of goal-directed action involve some kind of self-other identification. To see this, let us suppose that fully developed human conceptions of action link 'third person' and 'first person' representations of experiences of the action. So, such conceptions would link representations of an action's constituent acts and stereotypical situations of occurrence - including goal states, to information about motor sequences, kinaesthetic and other experiences. This could be done in such a way that a third- 
person experience of an action's constituent parts and stereotypical scenarios associated with it can be correlated with first-person experience.

To give an example, we can consider eating as an activity which very young children would have a concept of. We can assume that in the first instance, their conception of eating only co-ordinates first-person information, eg information relating to motor sequences (involved in masticating etc.) and to the sensations of taste. A more fully developed conception can be formed once the typical patterns of perceived actions of others eating and typical states attending eating have found their way into memory and have been associated with the corresponding first-person experiences. The typical actions would include: taking hold of the food, bringing it to mouth, chewing and swallowing it. Typical states associated with eating include those of the food being held in the mouth and its disappearance (down the alimentary canal).

The proposals in Simmons \& Barsalou (2003) concerning the representation of conceptual knowledge using convergence zones and cross-modal conjunction provide an appropriate means of cashing out what this 'association' of first- and third-person representations might amount to. It should be stressed that it is not necessary that some form of self-other identification is required on the part of one agent in order to recognise another agent as performing an action or to make inferences about the usual goal-states or other endstates. It is being proposed that representations of first- and third-person experiences of the agent are being co-ordinated and identified as being of the same action. The representing agent becomes attuned to regularities (constraints) between constituent acts and certain states (situation types). Even where those situation types are of first person experience (say of pleasure, sweetness etc) this does not call for some kind of analogical identification of self and other. All that is needed is that there be some distinction between the experiencing self 
and the experiencing other. Then the representation of the situation type (of say experiencing sweetness) can be attributed to either. Again, neurological evidence (see Pulvermuller 2001, Pulvermuller et al 2001, Simmons \& Barsalou 2003) provides suggestions for how this could come about. The current view is that the cortical representation of a sensory-motor experience can be activated in the absence of that experience. This seems to make it possible for an agent to have a concept of an experience that is independent of any particular agent including the self.

We are assuming that a concept can be formed initially in response to either first- or third-person experience. In the case of a concept of eating and other early action concepts, the formation of representations of first-person experience would precede those of what stereotypical constituent actions look like (from a third-person perspective) and of states of the world associated with these constituents. In this regard, it seems that memories of constituent actions may be built on patterns of movement associated with certain actions and children seem disposed to attend to such patterns from a very early stage (Meltzoff \& Moore 1977). It also seems that children 'parse' representations of actions into constituents which one might reasonably assume correspond to the same constituents a first-person representation of the same action would recognise (Baldwin et al 2001).

In novel situations, a child may observe various actions for which they have only partial first-person experience. In such cases the child may be inclined to attempt to perform the sequence of constituent acts, some of which they may have fully-fledged conceptions of and others of which they may not. In this imitative way they can develop a better conception of the action as a whole. Such activities are often perceived as pretend play. But this is pretense-as-practice. The child is really performing some subset of the constituents of the goal-directed action as if the other normal elements of the situation were in place without 
actually assuming or 'making as if' tokens of these features are present. It may be that this affinitive co-ordination makes human conceptions of action different from those of other species. It certainly promotes imitative learning at an exponentially greater level than in species lacking this kind of co-ordination.

In as far as we can accept that children begin to develop these affinitive conceptions of action from 9-12 months, we can build up a picture of the development of key communicative, social and psychological concepts using the ideas from relevance theory and situation theory sketched above. The first type of action we now consider is attending to.

\subsection{Attending to}

Following from Sperber \& Wilson's ideas about information processing, we could say that there is a parallel between concepts of eating and of attending to. Eating involves an agent, some nearby food, some actions resulting in the typical end state and certain experiences. Attending to similarly involves an agent, a nearby situation, certain typical actions (involving turning the head and holding the gaze) and experiences. The result of eating food is most often positive nutritional effects and experiences. The result of attending to a situation is often cognitively nutritional effects and experiences. With this conception of attending to, the world of shared situations and communication can open up to a child.

\subsection{Gaze Monitoring, Joint Attention and Shared Situations}

Just as food can be conceived of as something that people can eat and have positive experiences of, so can situations be conceived of as things to attend to and have positive experiences of. Just as a child will regard other people's eating a substance as a reliable guide to that substance's nutritional benefit (cf the less efficient method children also employ 
involving trying out any found object for nutritional value), so will another agent's attending to a situation be a fairly reliable guide to that situation's cognitive nutritional benefit. Just as a child can observe someone eating and wonder about the food being eaten, what it would be like to taste etc, so a child can observe someone attending to something and wonder about the situation being attended to, what it would be like to process, as it were. Gaze monitoring, then can be seen as a matter of monitoring the actions of another agent (presumably in the hope of cognitive effects).

One interesting difference between the eating case and the gaze monitoring case involves identifying the third object in question. Unlike with food, it is not obvious exactly which situation another agent attends to. Here we assume that the relevance mechanism does its work. The child will turn their own attention in roughly the same direction as that of the other agent, focussing on a situation which yields a level of cognitive effects for the effort expended which is set by the relevance mechanism.

Though joint attention is often accompanied by gaze monitoring of the agents involved, it is being proposed here that joint attention itself is simply a matter of two agents attending to a situation in a shared situation. A shared situation contains an element of circularity, supporting the fact that the agents attend to the shared situation itself (see Barwise 1989b). In general, a situation shared between $\mathrm{a}_{1}$ and $\mathrm{a}_{2}$ who are in relation $R$ (eg kissing) will be of the form:

$$
\begin{aligned}
& \mathrm{s}_{\mathrm{sh}} \models<\mathrm{R}, \mathrm{a}_{1}, \mathrm{a}_{2}, \mathrm{l}_{1}, \text { yes }> \\
& \mathrm{s}_{\mathrm{sh}} \models<\text { attend, } \mathrm{a}_{1}, \mathrm{~s}_{\mathrm{sh}}, \mathrm{l}_{2}, \text { yes }> \\
& \mathrm{s}_{\mathrm{sh}} \models<\text { attend, } \mathrm{a}_{2}, \mathrm{~s}_{\mathrm{sh}}, \mathrm{l}_{3}, \text { yes }>
\end{aligned}
$$


It seems reasonable to suppose that the kissing described by the implicitly reflexive verb appearing in 'The lovers kissed' is an activity which involves a shared situation as an (almost) essential feature. This is what we are also assuming for joint attention, if only in the sense in which this term is employed in current theoretical and developmental discourse. We can represent joint attention as in (6) where $\mathrm{s}_{\mathrm{ja}}$ is a shared situation and $\mathrm{s}_{\text {object }}$ the object of shared attention, $\mathrm{a}_{1}$ and $\mathrm{a}_{2}$ are the agents :

$$
\begin{aligned}
& \mathrm{s}_{\mathrm{ja}} \equiv<\text { attend, } \mathrm{a}_{1}, \mathrm{~s}_{\text {object }}>\wedge<\text { attend, } \mathrm{a}_{2}, \mathrm{~s}_{\text {object }}> \\
& \mathrm{s}_{\mathrm{ja}} \equiv<\text { attend, } \mathrm{a}_{1}, \mathrm{~s}_{\mathrm{ja}}>\wedge<\text { attend, } \mathrm{a}_{2}, \mathrm{~s}_{\mathrm{ja}}>
\end{aligned}
$$

In as far as joint attention requires just a shared situation, an agent could engage in that activity without there being any mutual knowledge involved. Although shared situations are a source of mutual knowledge (see Barwise 1989b), such knowledge would only be available relative to constraints the conceptualisation of which require folk-psychological abilities. To get from a shared situation to mutual knowledge we need a constraint which features another shared situation, one in which both agents have the appropriate cognitive abilities - some kind of representational theory of mind. ${ }^{9}$ Indeed, nothing much follows for an agent from their representing themselves as being in a shared situation unless many other assumptions are made. Recall that we have characterised attending to such that one can attend

\footnotetext{
${ }^{9}$ Where young children engage in joint attention, we may unreflectively assume that
} they are sharing information. We should take heed of Povinelli \& Giambrone (2001) who suggest that the appearance that apes engage in deception results from our (more or less unreflective) attribution of psychological abilities to apes. 
to a situation, $\mathrm{s}$, in which some state of affairs, $\sigma$, obtains, and not get the information that $\sigma$ obtains in s (see Simmons \& Barsalou 2003 for an account of how this may happen). To get or have information about s (that $\sigma$ obtains) the relevant channels to the agent's cognitive system have to be open.

Given how finely we can discriminate states of affairs, there is a well-known doubt about whether a rational agent could ever know that information is actually shared. While it is very difficult to share information, it is very easy to share situations. For even though situations may be as finely individuated as states of affairs, when engaged in some way with another agent, attentional sweeps of the locale by both parties will result in the existence of many locally shared situations. Given the ubiquity of shared situations where two agents are interacting, and given the possibility of classifying situations using parameters, an agent would have reasonable grounds for assuming the existence of shared situations (as in (7)) and could thereby extract some relevant information from such situations.

$$
\begin{aligned}
& \exists \mathrm{f}, \mathrm{s}_{\mathrm{sh}} \mathrm{s}_{\mathrm{sh}} \models<\mathrm{R}, \mathrm{a}_{1}, \mathrm{a}_{2}, \mathbf{l}_{1}, \text { yes } / \text { no }>\wedge<\text { attend, } \mathrm{a}_{1}, \mathrm{~s}_{\mathrm{sh}}, \mathbf{l}_{2}, \text { yes }>\wedge<\text { attend, } \mathrm{a}_{2}, \mathrm{~s}_{\mathrm{sh}}, \mathbf{l}_{3}, \text { yes }>\wedge \\
& <\mathrm{P}_{1}, \mathbf{l}_{\mathbf{1}}>\wedge<\mathrm{P}_{2}, \mathbf{l}_{\mathbf{2}}>\wedge<\mathrm{P}_{3}, \mathbf{l}_{\mathbf{3}}>[\mathrm{f}]
\end{aligned}
$$

(7) says that there is a shared situation and assignment of values to parameters such that interaction $R$ took place at a spatio-temporal location falling within the relevant bounds fixed by $P_{1}$ and where the spatio-temporal bounds of the locations of the attending by each agent are similarly narrowed down as much as is relevant. ${ }^{10}$ That is, it says that there is a shared

\footnotetext{
${ }^{10}$ Note that some versions of situation theory would allow for a unique maximal situation (a world) and it may seem that such a situation could always be shared among all of
} 
situation in which $R$ takes place between $a_{1}$ and $a_{2}$.

Shared situations are also a source of what Sperber and Wilson call mutual cognitive environments. A mutual cognitive environment is a set of manifest assumptions shared by a group of individuals which also includes assumptions about who shares them. Manifestness for $\mathrm{x}$ is a property of assumptions which are capable of being represented by $\mathrm{x}$ as true or probably true. Assumptions in a mutual cognitive environment are said to be mutually manifest. As with mutual knowledge, the difference between shared situations and mutual cognitive environments is that forming any conception of the latter would require folkpsychological abilities - manifestness having more or less the same accessibility relation as belief.

Mutual manifestness plays a criterial role in Sperber \& Wilson's characterisation of communicative situations. By replacing the notion of mutual manifestness with that of shared situations in a relevance-theoretic account of communication one can see how children can truly grasp the explicit or overt dimension of communication without any sophisticated modal abilities. We shall return to this issue below after we consider other-directed and benevolent actions.

\subsection{Action on Another, feeding and directing attention}

Action directed toward another agent does not require any cognitive abilities to form a conception of other than those required for action concepts generally. For example, kissing and feeding would be conceived of in terms of constituent acts on the part of one agent

its sentient inhabitants. But we assume that there are limits on what one can attend to and that attention is limited to 'local' or at least non-maximal situations. 
directed towards another. An adequate conception of a feeding situation could just involve the act of offering food (putting the food before the second agent) in a shared situation and the offered food being eaten. I.e. the offering would be a simple other-directed action, while the eating would be an optional separate act. Although feeding typically involves compliance on the part of the second party, it is not necessary to posit a class of joint actions with any special properties (cf Clark 1996). What does seem necessary is that other-directed action such as feeding takes place in a shared situation.

As with the analogy between eating and attending to, there is a good analogy between feeding and showing or directing attention. Directing attention is a matter of offering a source of relevance with a gesture and the second agent attending to the relevant situation. As with gaze monitoring and joint attention, the problem of co-ordination is resolved on the part of the second agent by its relevance mechanism. Once this agent's attention/gaze is aligned with that of the gesture, the mechanism will fix on a situation which yields enough cognitive effects to be worth the effort disbursed.

Like feeding, directing attention is basically a benevolent act. Why it is that children themselves come to show things to others is not clear - but nor is it clear why they offer food or engage in other reciprocating benevolent behaviours. It seems to be instinctual.

\subsection{Communication}

Here is a minimalist relevance-theoretic account of communication: following Sperber \& Wilson we can accept that a basic act of communication involves one agent drawing another agent's attention to something. On the minimalist account, that something is a situation. The prototype for the concept of communication includes one agent drawing another agent's attention to a situation in a shared situation. As the communicative situation is a shared 
situation, it is a potential source of mutual knowledge or mutual manifestness.

Before considering the differences between this and Sperber \& Wilson's view, there is a further analogy to be drawn between communicating and feeding. Just as an agent may be taking themselves to be offering food but be mistaken, so an agent may take themselves to be drawing someone's attention to a situation, but the situation does not exist. And just as non-food may have an ill-effect on an agent who accepts it, as Sperber \& Wilson observe, mis-information can have a negative effect on the cognitive system which accepts it.

However, we assume that the cognitive system has an 'immune system' whereby information obtained is treated with varying degrees of certainty depending on its source - directly perceived information being the most secure, inferred and socially received information less secure.

\subsection{Different Relevance-Theoretic Views of Communication}

On the minimalist view being presented here we can say, in the spirit of Fodor (1998), that a communicative situation is that kind of situation which our concept of communication locks onto as a result of exposure to stereotypical instances of communication. Thus what we can say about such situations - and hence about human communication - depends partly on which aspects of our minds are involved in the locking-on process. In this section, a sketch of conceptual development has been given whereby a child younger than two years old - without folk-psychological abilities but with the ability to form action concepts, equipped with a relevance mechanism and with some kind of instinctual benevolent disposition - would be able to engage in, as well as respond to, basic communicative acts. This leaves us with a minimalist account of basic human communication involving an act of ostension with its concomitant gestures, an indicated situation and a shared situation. 
Though relevance theoretic assumptions about cognition and communication provide the basis for a minimalist account of basic communication, Sperber \& Wilson themselves tend to characterise even basic communication in terms which presuppose sophisticated psychological concepts. In particular Sperber \& Wilson (1986/1995) characterise communication in terms of a communicator acting to get the second party to recognise an intention to make mutually manifest an intention to make information manifest or more manifest.

Sperber \& Wilson's proposal regarding the structure of communicators' intentions is partly motivated by consideration of cases similar to those which led to the inclusion of a mutual knowledge condition into Grice's definition of meaning $g_{N N}$. They propose that the overtness or explicitness feature, which we agree is necessary for communication, requires the mutual manifestness condition. While this condition would account for the intuition, it is unnecessarily strong. This intuition can be captured within a minimalist account if we assume that basic communication is conceptualised as involving a shared situation where the communicator is drawing the other agent's attention to something. Intuitions about the many examples which motivate the overtness condition would then be explained as being due to the fact that in those deviant examples informants cannot reasonably assume that there is a shared situation in which an attention-directing gesture is made. That is, they cannot see any possibility for an assumption along the lines of (7) above (where $R$ is directing attention) to be made. Thus one can characterise the prototypical communicative situation without resorting to notions such as mutual knowledge or mutual manifestness.

Like Grice, Schiffer and others, Sperber \& Wilson also favour a mode of describing what goes on in communicative interactions in terms of one agent seeking to alter the mental state of another and in terms of the communicative participants viewing the ostensive actions 
as the offering of evidence for communicative intentions. But this is just one way in which more sophisticated agents may interact given the basic view of communication in relevance theory. There are other more and less sophisticated ways to interact communicatively which are consistent with this view.

\subsection{Language Use and Language Learning in Communicative Situations.}

Communicative acts most often involve the use of language. On the minimal relevancetheoretic account, it will be assumed that communicative language use is part of the directing gesture which the communicator makes, facilitating the second party's search for the situation being indicated. When communication involves a declarative sentence in its standard usage, the meaning of the sentence guides the audience in deciding what their attention is being drawn to. Let us assume that the meaning of a sentence determines a soa. For example, the sentence 'John is asleep' can be associated with the soa, <sleep, john, $1_{\text {now }}$, yes $>$ in an obvious way. The practice adopted by language users is to assume that the situation indicated by a communicative act is of a type which is subsumed by the soa determined by the sentence meaning. For example, a communicative act which includes the uttering of the sentence, 'John is asleep', is taken to be indicative of a situation which supports the soa, <sleep, john, $1_{\text {now }}$, yes $>$.

So, the proposal is that utterances of words and sentences are conceived of as constituents of ostensive acts, these constituent acts being descriptive of the type of the situation being indicated. From this perspective, we can say that pronouns and similar expressions are learnt as features of acts of referring to objects in the situation being indicated. There need be no Stalnakerian presupposition for the proper mastery of these basic forms, although it is open to sophisticated adults to make such presuppositions (eg that the 
referent of a pronoun is in the current object of the audience's attention - see Breheny 2004). Thus children, like anyone else, can engage in communicative activities without concerning themselves with speaker presuppositions, beliefs etc. The process of reference resolution for pronouns proceeds as a part of the larger task of fixing on the indicated situation - the choice of referent being a matter of obtaining a characterisation of this situation in accordance with what the relevance mechanism determines. In fact, although this minimalist account and Sperber \& Wilson's account differ in various respects, both accounts would treat the resolution of manifold indeterminacies in utterances in the same way (see Sperber \& Wilson 1986/95 and references cited therein). With the minimalist version we can see why children are as untroubled as adults by these indeterminacies (modulo the above-noted limitations for the former when it comes to employing assumptions about what is common ground and so forth).

\subsection{Co-ordination in Communication}

The picture of language use and communication thus far presented contrasts starkly with the code model mentioned in section 2.2. Unlike the code model, any relevance-based model leaves room for a certain degree of indeterminacy with regard to the precise co-ordination of the communicator's 'message' (what is being indicated) with what the audience recovers. However the indeterminacy inherent in this model reflects that which occurs in natural language use. That is, while there may be a fact of the matter about the interpretation of a given utterance according to the semantic rules, in as far as that utterance contains contextdependent expressions there will always be some indeterminacy on the part of the audience about what the object of the speaker's action is. Note that accounts which build in mutual knowledge (or mutual assumption) of contextual information as an essential feature of 
communication merely locate the indeterminacy involved in communication at the stage where choices are made about what is mutually assumed.

As Sperber \& Wilson observe, if communication is just guided ostension and we have a concept of relevance, then the rational strategy for the audience to adopt is to resolve the question of what her attention is being drawn to by first aligning her attention with the communicating gesture and then allowing her relevance mechanism to fix on the source of information which achieves the expected level of relevance. Having done so, the audience would be justified in assuming that the resulting situation attended to is the one the speaker was directing her attention to. The reasoning behind such a justification, like that involved in game theoretic accounts, involves a number of levels of higher-order expectations.

So, it should be emphasised that on any relevance-theoretic account, there is no denying that communication as a rational practice involves some kind of co-ordination among agents. But here the essential co-ordination is not on assumptions about contextual features (what is mutually assumed) but simply on the manner in which the audience will respond to the communicative act. And the manner of response is always the same: follow a path of least effort in fixing on a source of optimal relevance. Thus, given the developmental data, the virtue of this minimalist relevance-theoretic account is that it proposes that one would naturally but unreflectively conceptualise and respond to basic communicative acts in a manner for which there is rational justification were it to be sought. There would be no discontinuity between the communicative behaviour of children who would not be able to, on reflection, find rational justification for their behaviour and adults who could. So, in contrast to game-theoretic and other common-knowledge accounts, we can suppose that an agent can engage in basic communication and take herself to be so engaged without having to have the means to find rational justification for their choices because we do not define communicating 
as a kind of rational co-ordinating of signal and message.

In all likelihood, many of the kinds of phenomena, such as conversational implicature, that have so interested pragmatists involve agents employing the full range of their folkpsychological abilities and therefore lie beyond the abilities of young children. As already mentioned, experimental evidence suggests that children much older than four years do not 'get' scalar implicatures of the 'some/not all' variety. In general, sophisticated speakers and hearers will naturally make assumptions about the common ground to better ensure coordination of message and interpretation. However, while there is no doubting that much reflective activity of this kind goes on in communicative interactions, it seems clear from a relevance theoretic perspective that a basic act of communication is not necessarily one which involves one agent acting to affect the mental states of other agents, nor is it the case that common knowledge of relevant contextual information is an essential feature of communication.

\section{Strategy III: Squaring Conceptually Elaborated Accounts of Communication with Impoverished Conceptual Abilities of Communicators}

Until now, it has been assumed that if an account of some aspect of communicative language use includes propositional attitude-like states as essential features, then that account is undermined by the developmental data regarding folk psychology and communicative abilities. However, there are still two kinds of move open to proponents of a more elaborate view of communication which are worth considering. Each of these are different versions of strategy III. The first type of move would invoke some version of the idea of a 
communication module. The second move would be based on a general strategy for defending conceptually elaborate accounts of some cognitive phenomenon while allowing that agents do not necessarily employ the theorists' concepts in cognitive processes.

\subsection{A Communication Module}

Perhaps mindful of the developmental data, Sperber \& Wilson (2002) suggest that an inferential mechanism which is geared to processing stimuli from communicative acts may feature as a module of the mind. Although their modularist proposal could be construed in a number of ways, it seems fairly clear that Sperber \& Wilson envisage that the module in question comes into operation earlier than general folk-psychological abilities, but that the conceptual resources it contains are not 'available' to inferences about behaviour other than communicative behaviour. That is, young children do not have general folk-psychological abilities but they have the cognitive wherewithal to make complex inferences about the mental states of others when engaged in communicative interactions. If one has a Fodorian view of concepts, then the modularist version implies that what constitutes a communicative situation will be determined by this communicative module. As such, the basic communicative situation would necessarily feature the informative intentions of agents and possibly other attitudes.

Choosing between this modularist relevance view and the minimalist relevance position will amount to looking at what young children can do as communicators and looking at what abilities doing that would minimally require. If it can be shown that in the realm of communication children below four years really have to be making folk-psychological inferences, then the minimalist view would be compromised. However, thus far, there is no evidence that children below four years really do any better in the realm of communication 
when folk-psychological abilities are required. This much is in fact noted in Sperber (1994). On the contrary, experimental studies which clearly require subjects to employ folkpsychological abilities (eg to assign reference) suggest that children under four years fare no better in this domain than others. Consider for instance Mitchell et al's (1999) false belief task with descriptions outlined above, or the fact reported in Noveck (2001) and Papafragou \& Mussolino (2003) that children only grasp basic conversational implicatures well beyond the age of four.

A second possible modularist strategy would be to suggest that children have an innate Leslie-style mechanism which locks onto Gricean meaning ${ }_{\mathrm{NN}}$. So, although young children have a concept of meaning $g_{\mathrm{NN}}$ they may have little conception of what that is at first. There are two main considerations against taking this view given a viable minimalist alternative. The first consideration turns on the presumption by this second modularist view that speech acts are essentially as Grice proposed. In particular, it is presumed that they are essentially directed toward the attitudes of others. Given a viable alternative which can account for intuitions about 'communicating' or 'meaning' without folk-psychological elaboration, it does not seem necessary to define communicating as Grice did. The second point also relates to parsimony. A Leslie-style mechanism for Gricean meaning ${ }_{\mathrm{NN}}$ would have to be bound up with Leslie's mechanisms for belief, desire and other folk-psychological relations, since these relations are crucial to what meaning $g_{\mathrm{NN}}$ is supposed to be. Other concepts of actions - like kicking, kissing and feeding - would arguably be associated with mechanisms for locking onto these activities, but it does not seem necessary that these mechanisms have to be bound up with Leslie's Theory of Mind module. In fact, the mechanism described in section 5.2, which co-ordinate first- and third-person representations associated with these actions, arguably does the job. So, again, given that there is a minimal 
account of communicating and meaning which assumes only the simple mechanism for forming concepts of actions, it would have to be favoured for reasons of simplicity.

\subsection{Habituation to inference in conversation}

In both 'Meaning' and 'Logic and Conversation', Grice comments on whether he thinks that people actually employ the patterns of inference that his account of speaker meaning would lead us to expect. In both cases, Grice suggests that we do not necessarily go through all of the steps in the reasoning that would be involved. On the face of it, this kind of disclaimer undermines the explanatory relevance of Grice's account. We are assuming however, that Grice intended his account to have explanatory relevance and that he had in mind some way of reconciling these matters. However, it is not self-evident how this may be done. Indeed, it is suggested in Warner (2001) that Grice was often pressed on this question, which is broached in Grice (2001, chapter 1).

It seems that Grice had it in mind that reasoning was generally a matter of performing reason-preserving transitions between sets of thoughts. According to Grice, one can reason to a conclusion by going 'the long way' - working through all of the steps which take one from premise to conclusion, or it is also possible to go 'the quick way'. Going the quick way involves making intuitive jumps which preserve the soundness (satisfactoriness) of the long way. So, faced with a piece of communicative behaviour there are two things an agent may do. She may posit, among other things, that the speaker has an M-intention of some to-bedetermined description and proceed, by some kind of belief-desire inference to the best explanation, to a conclusion about what the speaker meant. That would be the long way. Alternatively, the agent may just make some intuitive leaps in arriving at some conclusion about what was meant. The intuitive leaps may be based on 'habituation' to the relevant 
patterns.

It is not clear whether someone can be counted as reasoning from premises to conclusion unless that person could go the long way if they wanted. However, let us assume that young children can become habituated to shorthand patterns of inference and apply those in their communicative interactions. In as far as we can convince ourselves that these individuals intend their jumps to be shorthand for some longer chains of reasoning and in as far as those chains necessarily involve M-intentions, then we can say that these children engage in meaning $g_{\mathrm{NN}}$ activities. Thus we would preserve the Gricean view of the nature of communicative interactions.

Putting aside questions of the general plausibility of this proposal, we can make some immediate comments. Firstly, there is a prima facie objection stemming from the abovementioned fact that children of this age do not understand or engage in conversational implicature in any way. This fact is problematic since the habituation proposal predicts no such distinction. If children's abilities with regard to conversation arise from their becoming habituated to the patterns of inference they adduce from adults' interactions, and given that, according to the Gricean model, what is implicated and what is explicit are recovered by inferences of the same type, then there is no reason why a child should not be disposed to infer, say, 'not all Fs G' on hearing 'some Fs G' in assertive contexts. But, while adults do make these inferences fairly routinely, children do not. This strongly suggests that children have to figure out for themselves that in saying 'some' a speaker would in the appropriate case be intending to indirectly indicate 'not all'. Given the ubiquity and relative salience of this kind of scalar implicature, the developmental data further suggest that, while children no doubt become attuned to the semantic conventions of their language, they do not so readily discern common patterns of pragmatic inference, where such inferences involves assumptions 
about the grounds - and therefore mental states - of other speakers.

The second point to be made about this habituation strategy has to do with how we think about what an interpretation of an utterance consists in. A Gricean would say that interpreting an utterance amounts to recovering what the speaker M-intended. This in turn amounts to recovering what the speaker meant $\mathrm{NN}_{\mathrm{N}}$ to say and implicate. We are assuming that children below four cannot arrive at conclusions of this type. So we must assume that whatever they think about the actions of other speakers (or their own actions) it cannot be represented in these terms. But we might wonder, at least in terms of 'what is said', what concepts a child employs to think about these actions and whether an account of interpretation in terms of these less sophisticated concepts may be possible. If it were, then the more minimal account would gain further support from these developmental facts.

It should be mentioned that there may be other ways of squaring a conceptually or inferentially sophisticated account of some activity where the participants do not necessarily manifest the requisite sophistication - without endorsing the view of Grice (2001). However, for any such account which endorse a conceptually elaborate analysis of communication, both of the above points apply. We still require children to become attuned to patterns of inference involved in communication and if those children are not themselves working things out 'the long way' we are still owed a story about why they can perform tasks which a minimalist account of communication would say calls upon no folk-psychological concepts necessarily while they cannot perform those tasks which would require thinking about propositional attitude states of others. Similarly, any such story would still need to posit concepts with which children could think about the communicative acts of others, and so would be at an explanatory disadvantage to a more minimalist account. 


\section{$7 \quad$ Conclusions}

The vast majority of communicative interactions, including interactions involving children below four years, are inexplicable on a simple code-model account. Action-oriented approaches to these interactions seem well-placed to yield an account of how these interactions proceed - given the continuity between non-verbal and verbal communication and given the predominant analysis of context-dependent expressions which include the referential actions of the speaker in the specification of their meaning. Gricean and contextco-ordination accounts of these interactions are based on analyses of communicative acts in terms which a significant minority of able communicators would not be able to conceptualise. In this paper, it has been argued that developmental data presents a more serious problem for these approaches than may have been thought. Moreover, when placed next to a viable, minimalist, action-oriented account of communication, the more elaborate views are at an explanatory disadvantage. If we adopt Sperber \& Wilson's basic idea that communicating is drawing attention to and we apply their theory of relevance and cognition, we can demonstrate how all language users conceptualise basic communication in the same way. In as far as this minimalist view is consistent with accounts of the many sophisticated interactions that take place in communicative situations, it has an advantage over more elaborate alternatives.

On the minimalist view presented here, 'communicating' (like 'feeding', 'kicking' etc) is a term for which there is no definition - real or nominal. The property being $a$ communicative act is mind dependent - in the sense of Fodor (1998). It is that property which minds like ours lock onto as a result of exposure to its prototypical instances. 
There is much more to be said about how this picture of communication can form the basis of an account of the variety of speech acts but, for reasons of space, this discussion has to be deferred. However a couple of brief suggestions of how the account would go seem to be in order. First, on the question of directive speech acts (questions, orders etc), it seems natural that a minimalist would see these in their most basic forms, or earliest manifestations, as instrumental speech acts whereby the speaker gets another agent to bring about a state of affairs; rather than as an expressions of a desire that a certain state of affairs be brought about.

Second, there are, of course, many different forms of less basic discourse involving declarative or indicative forms. While the unreflective type of basic communication described here occurs a lot more than most discussions of speech acts envisage, there is no denying that people often say things where the intention is more circumspect. A minimalist account of these speech acts would draw on the observation that it is always open to a speaker to draw her audience's attention to how she relates (epistemically, emotionally etc) to a situation she is drawing her audience's attention to. In Breheny (2002a,b) an account of conversational implicature is given in terms of these indirectly indicated situations - involving the directly indicated situation and the speaker. An account of more circumspect types of assertive speech acts can be given along these lines as well.

In situation theory, there is scope for a notion of possible situations (if only of possible maximal situations - i.e. worlds - see Barwise 1989a) and an account of modal discourse of various sorts (see Breheny 2004). In as far as fiction is a kind of modal discourse (see Lewis 1983) we expect that children below four may be prone to taking bed-time stories literally. Although there is some doubt about whether they are able to fully process episodic, narrative discourse at all. 


\section{References:}

Asher, N. 1999: Discourse structure and the logic of conversation. In K. Turner (ed), The Semantics/Pragmatics Interface from Different Points of View. Oxford: Elsevier Science.

Baldwin, D., J. Baird, M. Saylor \& M.A. Clark 2001: Infants parse dynamic action. Child Development, 73(3), 708-717.

Baron-Cohen, S., A. Leslie \& U. Frith 1985: Does the autistic child have a theory of mind? Cognition, 21, 37-46.

Barwise, J. 1989a: The Situation in Logic. Stanford, Ca.: CSLI.

Barwise, J. 1989b: On the model theory of common knowledge. In J Barwise, The Situation in Logic.

Barwise, J. \& J. Perry 1983: Situations and Attitudes. Cambridge Mass.: MIT Press.

Bloom, P. 2000: How Children Learn the Meanings of Words. Cambridge Ma.: MIT Press.

Bloom, P. \& T.P. German 2000: Two reasons to abandon the false belief task as a test of theory of mind. Cognition, 77, B25-B31.

Breheny, R. 2002a: The current state of (radical) pragmatics in the cognitive sciences. Mind and Language, 17, 169-187.

Breheny, R. 2002b: On the Dynamic Turn in the Study of Meaning and Interpretation. In J. Peregrin (ed) Meaning in the Dynamic Turn. Dordrecht: Elsevier.

Breheny, R. 2004: Indefinites and anaphoric dependence: A case for dynamic semantics or 
pragmatics? In M Reimer \& A Bezuidenhout (eds) Descriptions and Beyond. Oxford: OUP.

Carston, R. 2002: Thoughts and Utterances. Oxford: Blackwells.

Clark, H. 1996: Using Language. Cambridge: CUP

Fodor, J. A. 1998: Concepts. Oxford: OUP.

Gazdar, G. 1979: Pragmatics: Implicature, Presupposition and Logical Form. New York: Academic Press.

Gergely, G. \& G. Csibra 2003: Teleological reasoning in infancy: The naive theory of rational action. Trends in Cognitive Science 7(7), 287-292

German, T.P. \& A. Leslie 2000: Attending to and learning about mental states. In P. Mitchell \& K. Riggs (eds) Children's Reasoning and the Mind. Hove: Psychology Press.

Gopnik, A. \& H. Wellman. 1995: Why the child's theory of mind really is a theory of mind. In M. Davies \& T. Stone (eds) Folk Psychology. Blackwells: Oxford.

Gordon, R. 1995: Simulation without introspection of inference from me to you, In M. Davies \& T. Stone (eds) Mental Simulation. Oxford, Blackwell.

Grice, H. P. 1957/1989: Meaning. In The Philosophical Review vol 66 (reprinted in Grice 1989 pp 213-223)

Grice, H.P. 1969/1989: Utterer's meaning and intentions. Philosophical Review (reprinted in Grice 1989 pp 86-116)

Grice, H.P. 1989: Studies in the Way of Words. Harvard University Press.

Grice, H.P. 2001: Aspects of Reason Oxford: Clarendon.

Jeannerod, M. 2002: Consciousness of action and self-consciousness. A cognitive neuroscience approach. In J. Roessler and N. Eilan (Eds), Agency and self awareness: Issues in philosophy and psychology. Oxford: Oxford University Press. 
Jordan, M. \& S. Russell 1999: Computational intelligence, In R. Wilson \& F. Keil (eds), The MIT Encyclopedia of the Cognitive Sciences. Cambridge Ma., MIT Press. pp lxiii-xc.

Joseph, R. \& H. Tager-Flusberg. 1999: Preschool children's understanding of the knowledge and desire constraints on intended action. British Journal of Developmental Psychology, 17, 221-243.

Leslie, A. 2000: How to acquire a 'representational theory of mind'. In D. Sperber \& S. Davies (eds) Metarepresentation. Oxford : OUP.

Lewis, D. 1969: Convention. Harvard University Press.

Lewis, D. 1983: Truth in Fiction. In Philosophical Papers Oxford, OUP.

Lewis, D. 1994: David Lewis: Reduction of Mind. In S. Guttenplan (ed) A Companion to the Philosophy of Mind. Oxford, Blackwell.

Meltzoff, A. \& M. K. Moore 1977: Imitation of facial and manual gestures by human neonates. Science, 198, 75-78.

Mitchell, P., E.J. Robinson \& D.E. Thompson 1999: Children's understanding that utterances emanate from minds: using speaker belief to aid interpretation. Cognition, 72, 45-66.

Noveck, I. 2001: When children are more logical than adults: Experimental investigations of scalar implicature Cognition, 78(2), 165-188.

Nuti, M. 2003: Ethnoscience: Examining Common Sense. PhD Diss. University College London.

Parikh, P. 2001: The Use of Language. Stanford, Ca: CSLI.

Perner, J. 1991: Understanding the Representational Mind. Cambridge, Ma., MIT Press.

Povinelli, D. \& S. Giambrone 2001: Reasoning about beliefs: A human specialisation. Child Development, 72, 691-695.

Putnam, Hilary 1975: The meaning of 'meaning'. In K. Gunderson (ed) Language, Mind and 
Knowledge, Minnesota Studies in the Philosophy of Science, VII. Minneapolis: University of Minnesota Press.

Pulvermuller, F. 2001: Brain reflections of words and their meanings. TRENDS in Cognitive Sciences 5, 12, 517-523.

Pulvermuller, F. M. Härle \& F. Hummel 2001: Walking or talking?: Behavioral and neurophysiological correlates of action verb processing, Brain and Language, 78, $143-168$.

Schiffer, S. 1972: Meaning. Oxford: OUP

Simmons, W.K. \& L. Barsalou 2003: The similarity in topography principle: Reconciling theories of conceptual deficits. Cognitive Neuropsychology, 20, 451-486.

Sperber, D. 1994: Understanding verbal understanding. In Jean Khalfa (ed.) What is Intelligence? Cambridge: Cambridge University Press.

Sperber D. \& D. Wilson 1986: Relevance: communication and cognition. Oxford: Blackwell. (2nd edition 1995).

Sperber, D. \& D. Wilson 2002: Pragmatics, Modularity and Mind-reading. In Mind \& Language, 17 (1\&2), 3-23.

Stalnaker, R. 1979: Assertion. In P. Cole (ed.) Syntax and Semantics vol. 9: Pragmatics. New York: Academic Press.

Stalnaker, R. 1998: On the representation of context. Journal of Logic, Language and Information, 7

Stanley, J. 2000: Context and logical form. Linguistics and Philosophy, 23, 391-434.

Tomasello, M. 1995: Joint attention as social cognition. In C. Moore \& P. Dunham (eds), Joint Attention: Its Origins and Role in Development. Hillsdale, NJ: Lawrence Erlbaum. 
Tomasello, M. 2000: Perceiving intentions and learning words in the second year of life. In M. Bowerman \& S. Levinson (eds) Language Acquisition and Conceptual Development. Cambridge: CUP.

Tomasello, M. \& H. Rakoczy. 2003: What makes human cognition unique? From individual to shared to collective intentionality. Mind \& Language, 18, 121-147.

Warner, R. 2001: Introduction. In H.P Grice Aspects of Reason op cit.

Wellman, H. M. 1990: A Child's Theory of Mind. Cambridge, Ma.: MIT Press.

Wellman, H. M., D. Cross \& J. Watson 2001: Meta-analysis of theory-of-mind development: The truth about false belief. Child Development, 72, 655-684.

Wimmer, H. \& J. Perner 1983: Beliefs about beliefs: representation and the containing function of wrong beliefs in young children's understanding of deception. Cognition, $13,103-128$.

Zaitchik, D. 1990: When representations conflict with reality: The preschooler's problem with false belief and false photographs. Cognition, 35, 41-68.

Department of Linguistics

University College London 